\title{
Suggestions for Fire Protection Publicity and Education Work in China \\ Helan Wang ${ }^{*}$, and Jiang Zhu \\ Information Research Center, Shanghai Fire Research Institute of MPS of China, Shanghai, 200438, China \\ * Corresponding author: Helan Wang, Associate Research Fellow, wang_helan@163.com
}

\begin{abstract}
Targeting at the problems found in the current fire protection publicity and education work in China under the educational objective of acquiring and developing fire safety capacities and based on the status quo of fire protection publicity and education and public management in China, this article studies the principles for individuals to acquire and develop fire safety capacities and the relevant requirements on the measures of fire protection science popularization and education, probes the principles for making fire protection science popularization and education measures covering instruction, practice, examination, and management which comply with the principles for the public to acquire and develop fire safety capacities. It also develops facilities for fire protection science popularization and education covering instruction, practice, and examination, and proposes solutions for implementing fire protection science popularization and education in cities and public spaces such as communities and schools based on the status quo of fire protection publicity and education and public management in China. In addition, the article further proposes a solution on how to effectively promote "Seven Advancements" in line with the objective of acquiring and developing fire safety capacities as 9 ministries and commissions of China's central government have presented their opinions on the promotion of "Seven Advancements" regarding fire protection publicity and education.
\end{abstract}

Keywords: fire protection; publicity and education; measures of popularization and education;safety capacities; China

\section{Introduction}

Aiming at the problems existing in the work of fire protection publicity and education in China, and the present requirements presented by Chinese state and government, this paper try to work out some solutions for solving the problems and answering the requirements, and to achieve the object of carrying out effective fire protection publicity and education, through following series researches:

- How to acquire and develop public fire safety capacities?

- What kinds of measures can guarantee the acquisition and development of fire safety capacities of the public?

- How to guarantee all those measures to be implemented for all the public?

Finally, some suggestions about how to advance the Seven Advancements and how to further uphold it effectively were given in this paper. 


\section{Existing Problems Concerning Fire Protection Publicity and Education in China ${ }^{1}$}

Efforts on popularization of fire protection general knowledge and enhancing the public's fire safety awareness are insufficient; the publicity activities have no well-defined target groups, are not practical to the public's fire safety demand, causing it hard to understand, learn and remember; exploration towards the application of emerging media such as the Internet is lagging behind, the publicity means is simple rather than diversified and the publicity depth and extent are not sufficient; the fire protection training does not involve many social organizations and individuals, only provided by the fire department in most areas, while the training channels have not been diversified and the training participation is low, failing to meet the demand for fire protection talents.

\section{Seven Advancements in Fire Protection Publicity and Education}

On August 6, 2015, nine ministries and commissions of China's central government, namely, Central Network Security and Information Technology Leading Group Office, Ministry of Public Security, Ministry of Education, Ministry of Civil Affairs, Ministry of Agriculture, Ministry of Culture, National Health and Family Planning Commission, State Administration of Press, Publication, Radio, Film and Television and State Administration of Work Safety jointly issued the Guiding Opinion on the Work to Promote the Fire Safety Publicity and Education in Government Offices, Schools, Communities, Enterprises, Villages, Families and Internet. $^{2}$

The Opinion well defines the work objectives and focuses of the fire safety publicity and education in government offices, schools, communities, enterprises, villages, families and Internet, puts forward the requirements that local governments and relevant organizations should incorporate fire safety publicity and education into national security education system, and further identify the work responsibilities with respect to fire safety publicity and education of governments and functional departments of all levels, and social organizations, increase the efforts on public welfare publicity of fire safety in media, and upgrade the citizens' fire safety related legal consciousness, fire safety knowledge popularization rate and fire prevention and rescue capacities.

\section{Requirements Presented by the State and Government in China for Fire Protection Publicity and Education}

It should adhere, on one hand, to the special crack-down and regulation and improvement activities, on the other hand, to the root and basic work to innovate the social public security prevention and control system, optimize the social environment for public safety management and solve the root problems influencing social security and stability; under the principle of people first and life first, supervise in a full range the implementation of safety production accountability system and management, prevention and control, supervision, inspection and reward and punishment measures, well define the leadership responsibility of party committees and governments of all levels, the supervision responsibility of relevant departments and subject responsibilities of enterprises; adhere to the guideline of gravity center, resources and guarantee moving downwards along the whole governing structure to realize the reticulation and integration of security supervision and law enforcement and comprehensive government in urban and rural areas. 
To stabilize overall fire situation and guarantee public fire safety is the most basic requirements from the public to the fire department. Presently, China undergoes a rapid social and economic development, and urban construction moves towards high rising, complicated and large buildings. Faced by the situation of upward and downward extension in buildings, how to put forward the prevention and control criteria and increase fire prevention efforts?

It requires more efforts input on the fire safety publicity and education. The fire safety publicity must begin with the cultivation of fire safety awareness and enhanced warning education in children via television and Internet so as to build up the perceptual knowledge of the public in their mind. It is advisable to employ various media and various forms to vigorously popularize the fire safety knowledge and skills. "Seven advancements" of fire safety publicity are both seven transmission channels and seven work fronts. The key point for the current work is "how to advance the seven advancements and how to further uphold it effectively" to change the professional knowledge of fire safety into general knowledge shared among the public and in their life. It also needs to expand publicity channels. In addition, intensified training should be given to key groups covering people responsible for fire safety, management, full-time and part-time fire fighters, control room operators, security guards, electric welders and so on to get them well understand fire safety and further promote the upgrade of the fire safety capacity of their own work unit and the whole society.

\section{Overall Suggestions on Increasing Efforts for Supporting Studies of Fire Protection Publicity and Education by Fire Research Institute}

(1) The fire department, presently mainly responsible for the fire safety publicity and education in China, can not undertake the further fire safety publicity and education work due to limited staffing and great workloads of fire protection and prevention;

(2) The fire safety publicity and education is targeted at all the masses, featuring a great wide range and diversity of the objects;

(3) The objective of fire safety publicity and education is to improve the fire safety awareness and skills, that is, to improve the public's fire safety capacities. Since to receive fire safety education and finally to acquire fire safety capacities is a complicated and multi-development course, the fire safety publicity and education should be widespread and lasting efforts supported by series educating measures.

In view of the above reasons, to clear up the problems of fire safety publicity and education should involve the study strength of relevant institutes such as fire research institute as the fire department alone is never able to deal with the demanding fire safety publicity and education targeted at the whole public and for the objective of acquiring and upgrading fire safety capacities. It is suggested that more supports be given to the studies of publicity and education by the fire research institute. The studies should be provided with sufficient funding and policy support to work out scientific, effective and executable public fire safety publicity and education facilities and proposals and then have them available to the fire departments and relevant social organizations.

Effective solutions to all the above problems never come from some few efforts; rather, it demands a great amount of scientific researches to obtain the following countermeasures:

(1) Education measures and implementation plans with clearly defined target groups and closely related to the public's fire safety demand for the far ranging masses with so huge 
differences.

(2) Popularized teaching materials and facilities and teaching implementation plans and supporting policies and systems development plans based on the demand of fire safety education effectiveness for better understanding, learning and remembering.

(3) Various forms of publicity based on emerging media such as Internet to expand the publicity depth and range.

(4) Forming an effective closed-loop management and education implementation network involving the whole society's resources and covering the whole public by implementing national policy support, local government's contact management and network management, obligations of relevant employers and communities for ensuring their employees or residents to receive fire safety education, management education system with intermediate agencies and volunteers providing courses and training and uniform organic coordination and uniform deployment via the big platform of public fire safety publicity and education management information system. This will effectively solve the problem of "the fire protection training does not involve many social organizations and individuals, only provided by the fire department in most areas, while the training channels have not been diversified and the training participation is low, failing to meet the demand for fire protection talents”

How to put forward the prevention and control criteria and increase fire prevention efforts? The answer is to effectively carry out the fire safety publicity and education among the children and the whole public based many research efforts, so as to truly improve the fire safety capacities of the public, dramatically decrease the probability of fire and reduce life and property losses.

\section{How to Carry out Effective Fire Protection Publicity and Education}

The fire safety publicity must begin with the cultivation of fire safety awareness and enhanced warning education in children via television and Internet so as to build up the perceptual knowledge of the public in their mind. It is advisable to employ various media and various forms to vigorously popularize the fire safety knowledge and skills.

To acquire fire safety awareness and skills is to acquire relevant fire safety capacities. The objective of fire safety publicity and education is to upgrade the fire safety capacities of the public. This paper, based on this objective, will discuss what kinds of plans are scientific, reasonable and effective to be implemented.

The layout of discussion is as illustrated in "Fig. 1."

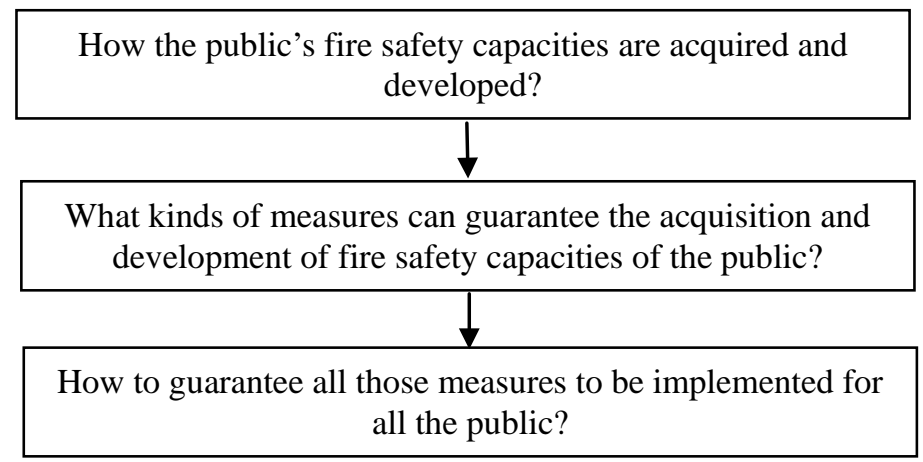

Fig. 1 - Layout of discussion 
First, it describes what processes involved in the course from the public receiving fire safety publicity and education to finally acquire and develop the fire safety capacities of the public themselves; then what kinds of publicity and education measures are required during the acquisition and development of such capacities to guarantee such acquisition and development, where the differences of the vast masses as well as the practical requirements should be considered; finally, how to guarantee those measures to be implemented for all the public in consideration of such far ranging people group, that is, it mainly comes down to the problem of fire safety publicity and education management system and implementation guarantee mechanism.

Below is the detailed description of each discussion layer.

\section{How to Acquire and Develop Public Fire Safety Capacities ${ }^{3}$}

The acquisition of public fire safety capacities involves four stages, namely, external influence stimulus from fire safety publicity and education, subject reaction equilibrium, internal contradiction movement and individual behavior modification.

The four stages mentioned are the necessary process for the acquisition and development of each fire safety capacity, while some capacities may be acquired via one circle and some requires several circles.

\section{What Kinds of Measures Can Guarantee the Acquisition and Development of Fire Safety Capacities of the Public?}

\subsection{Types of fire safety popularization and education measures supporting acquisition and development of public fire safety capacities}

(1) Stage of external influence stimulus: publicity and education via banners, broadcasting, and laws and regulations communication.

(2) Stage of subject reaction equilibrium: laws, regulations, administrative codes, etc.

(3) Stage of internal contradiction movement: training and experience, law and regulations requirements, publicity, etc.

(4) Stage of individual behavior modification:

1) Identify fire safety problems: providing specific fire safety popularization and education measures to get the public understand the fire safety problems with respect to the public themselves and the surrounding environment.

2) Select behavior route and forms under the restriction of fire safety motivations: studying and obtaining scientific fire safety behavior modes for specific requirements in specific occasions and further providing education and training to the public.

3) Externalize the fire safety motivation into behavior in practice activities of fire safety and develop the behavior into a habit in repeated reinforcement of such behavior: developing relevant guarantee systems, carrying out regular inspection and assessment to make the public to have repeated practices with their acquired safety knowledge and skills in their work and life to finally form their own habitual behavior. 


\subsection{Principles of developing and implementing fire safety popularization and education measures}

According to the rules of public fire safety capacity acquisition and development, such acquisition and development involves four stages of movements and developments. To ensure the final acquisition of the fire safety capacities, firstly, relevant measures should be in place to guarantee the realization of the development of the first stage, followed by the implementation of relevant measures to guarantee the realization of the development of the further three stages.

Therefore, targeted series of supporting fire safety publicity and education measures are the necessity to guarantee the ultimate acquisition and development of the public fire safety capacities.

According to the types of fire safety popularization and education measures supporting the four stages of acquisition and development of fire safety capacities, and to meet the requirements of the four stages, full-process measures of educating, practicing, examining and managing for supporting fire safety popularization and education should be implemented:

Educating (including publicity means): to have the public to acquire relevant fire safety knowledge and skills, to cultivate the emotion and determination towards fire safety belief, and to be willing to overcome bad habits of themselves and force themselves to conduct as per relevant fire safety requirements;

Practicing and examination: to have the acquired fire safety knowledge and skills securely kept in mind and make the public able to apply them skillfully;

Managing: to make the relevant fire safety behaviors acquired to become subconscious behaviors through repeated practices in daily work and life by virtue of mandatory requirements.

With the implementation of those measures, the public is expected to react in compliance with the fire safety requirements automatically in their daily work and life or when facing a fire, and so they truly acquire relevant fire safety capacities.

Especially when in a fire, the public is facing a test which is a life-and-death matter. Nothing can come into the mind in such a moment of death even they have much knowledge about fire safety, if they don't have repeated practice and turn the knowledge into subconscious behavior, they cannot think what steps to be taken. Of course, a fire will not give you some time to think how to react. On the other hand, if a man has practiced repeatedly as required by fire safety rules and regulations, and the acquired fire safety skills have been turned into subconscious behavior, he will automatically have safe behavior when in a fire.

\subsection{Introduction of educating, practicing and examining related facilities for publicity and education researched by the project team of our unit}

There are many forms of educating, such as the publicity and education via banners, broadcasting and laws and regulations and administrative codes. Among them, the systematic fire safety publicity and education in school is the most appreciate and effective one.

To help schools carry out systematic fire safety publicity and education, the project team, through unremitting efforts, has gain project and funding supports and developed the following teaching materials and popularization products and their implementation plans 
meeting the educating, practicing and examining work requirements and targeted at the teachers and students for the purpose of fire safety publicity and education:

- Editing of comprehensive coaching and training materials for campus based fire safety popularization and education;

- Research and construction of fire safety education virtual experience cabin;

- Research and development of fire safety knowledge online examination system.

Below is the detailed description of such education facilities and system.

\subsubsection{Comprehensive coaching and training materials for campus based fire safety popularization and education}

An investigation with nearly 20 primary schools in Shanghai reveals that the Shanghai primary schools generally lack of comprehensive fire safety capacity education materials. Comprehensive studies have been made from relevant theoretical knowledge, fire hazards and their prevention and control and corrective actions, fire emergency plan and evacuation drill plans, fire escape knowledge, skills and simulation drill and training acquisition methods, school fire escape related equipment and recommendation of equipment configuration, social fire safety activity program and school member participation mode, and relevant school rules and systems construction as per the demand of different stages of individual capacity acquisition and development on the fire safety popularization and education measures, and all inclusive fire safety knowledge and skills necessary for primary school fire safety education and management are obtained therefrom, based on which knowledge points are extracted and marked with stars as per the importance of the knowledge points, and finally primary school fire safety knowledge system is established; in addition, simple expression of primary school fire safety knowledge is studied as per the physiological and psychological characteristics of the faculty and students of primary schools, and teachers' book (besides for delivering lectures to students, the teachers' book also includes all fire safety management related knowledge and requirements of primary school, such as configuration of fire protection facilities, system construction, teacher cultivation, teaching plan, etc.), students' book with “a corn unwilling to be popcorn” as subject thread, as well a package of coaching and training materials for primary school based fire safety popularization and education incorporating demonstration lecture and auxiliary explanation PPT, pictures and video CD.

The faculty can depend on the teaching material guidance to use fire safety knowledge points, or have ease to edit their teaching plan with the help of the demonstration lecture and relevant materials stored in CD; leaders and teachers of all levels in the school further can establish fire safety systems and determine various campus fire safety management and education measures by virtue of the teaching material guidance so to guarantee a long lasting fire safety education and develop good fire safety capacities in teachers and students.

It is planned to complete the research of training materials supporting fire safety popularization and education for each schooling period from kindergarten to university based on the first draft of primary school teaching materials, and then such training materials will be published and distributed in a uniform format. Ambitiously, those materials are expected to be listed in the school books directory of schools of all levels.

The objective of this set of teaching materials is that: all schools, including those schools giving most priority to entrance rate, are able to carry out the fire safety education for all their 
teachers and students in a more effective way than the situation without coaching and training materials but collecting those materials themselves, obtain proper guidance on how to guarantee and manage the campus fire safety and truly improve the fire safety capacities of the whole teachers and students with the application of our all inclusive and user-friendly teaching materials, when they have to carry out the publicity and education works as required by the Law of Fire Protection and relevant themed educations concerning campus fire safety and so on.

This project is in line with the requirement that fire safety publicity and education should start from the children.

\subsubsection{Fire safety education virtual experience cabin}

The fire safety education virtual experience cabin is researched and developed for the purpose of helping the public to acquire relevant fire safety knowledge and skills.

The system is a closed virtual fire escape experience environment constructed as per the requirements of on-site simulation experience in fire safety education theories. In this system, a high lumen (up to $30,000 \mathrm{LM}$ at $360^{\circ}$ ) virtual fire environment is projected by a $120^{\circ}-360^{\circ}$ high-gain narrow-perspective metal frame curtain. Further, with the configuration of environmental temperature simulation equipment with a max power of $12,000 \mathrm{~W}$ (environmental temperature change within $60 \mathrm{~s}$ is $60^{\circ} \mathrm{C}$ ) and harmless smoke generating equipment, the system can simulate fire scenes in a true to life way to meet 3I requirements of virtual simulation. Subjects are divided into first person active subject and third person passive subject, the former wears 1080DPI HD OLED panel virtual helmet and several movement detection and record equipment on head, both hands, limbs and trunk, and can make free movements without script in the virtual fire environment. In the system, the first person active subject reacts with the environment and is subject to the influence of the environment so to gain the effect of virtually experiencing fire escape.

The system has the following innovations: 1) application of immersive virtual simulation in fire safety education; 2) simulation calculation of material burning speed in full-scene immersive virtual scene; 3) application of high-gain narrow-perspective metal curtain in virtual environment simulation; 4) modular-based split virtual full-scene immersive experience equipment; 5) fire escape experience involves all occasions in a school including classroom, cafeteria, library, corridor and playground, covers all key escape skills and escape route setup, and provides all-link route from occurrence of a fire to escape to designated site on the playground and sign in with the teacher to overall evacuation plan. "Fig. 2."
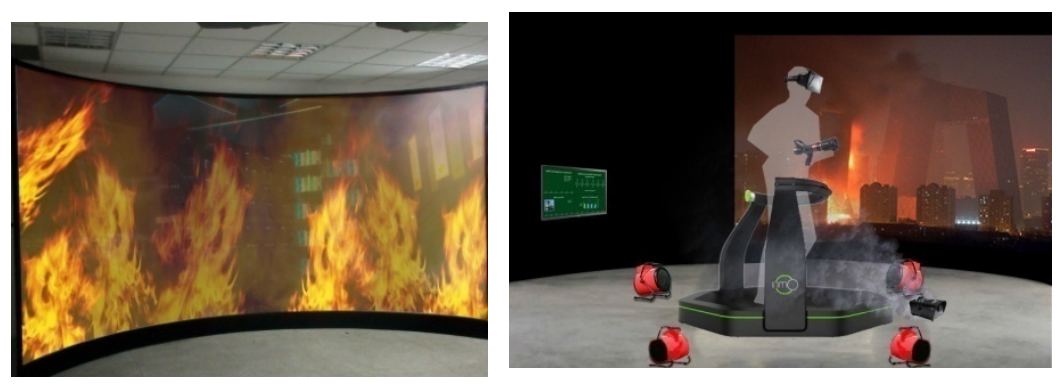

Fig. 2 - Virtual scenarios by virtual experience cabin of fire safety education 


\subsubsection{Fire safety knowledge online examination system}

The fire safety knowledge online examination system developed by the project team has the following innovations: 1) C/S architecture, accessible both via WAN and LAN and able to run on the special network of the public security department; 2) various document numbers can be imported through backstage to be used as learning and examination taker management entrance; 3) examination question library covers all aspects from learning of fire safety knowledge required by the whole course of public fire safety capacity acquisition and development, to skill training, from fire prevention to initial fire fighting, from fire hazard prevention and control to safety system construction. There are required questions and randomly sampled questions; 4) examination paper can be generated randomly and the order of questions is also randomly determined for each user logging in; 5) the examinee can make marks on the questions and a prompt can be given if there is any question not answered when the examinee is to submit the paper; 6) examination score is generated immediately upon the completion of the examination and can be printed at the teacher's terminal; 7) backstage management function enables the teacher to conduct various classification management for students, including class, ID number and score classification, as well as score statistics.

\section{How to Guarantee All Those Measures to Be Implemented for All the Public?}

\subsection{Suggestions for full-coverage public fire safety publicity and education system \& mechanism $^{3}$}

With reference to the advanced experience of Beijing, Shanghai and so on, it is suggested that the sub-district offices of all cities across the country strive hard for establishing "reticulation" mode, forming a three-level reticulation management mode, including a big reticulation for sub-district level, an intermediate reticulation for community-based administrative village, and a small reticulation for residential building and residential yard, community, village formation or natural village, large production and operation business, public high rise, large complex building or specific key prevention and control area, and finally establishing a fire prevention and control supervision and education network featuring "there are fire safety supervisors for each administrative area, full-time fire safety policeman for community, fire safety management assistor for reticulation and fire safety coordinator for each organization in place".

Further, by virtue of the construction of smart city, and with the application of Internet of things and big data, supervision and monitoring can be provided all the year round without ease and dead corner. Each organization can implement social fire safety regulation and education, training and examination, information input, statistics, analysis and tracking guiding and the like features based on the social fire safety regulation and education management information system platform which is based on ID card management information system, so to improve management and education efficiency and progressiveness and further realize full coverage of education and management.

For the specific operation, experience of Shanghai city can be learned to establish a top administrative organ similar to fire safety committee. Under the framework of the administrative organ, all member organizations will work together to implement entity-based operation and promote social resources involvement and multi-unit cooperation, based on 
which it is expected to form a multi-unit linkage long-acting mechanism with defined responsibility and extensive participation and to fully implement the mechanism of public fire safety popularization and education.

To meet the far ranging and long acting requirements of public fire safety education, the urban public fire safety popularization and education scientific management system and implementation mechanism plan are suggested: governmental agencies involved in public fire safety education are responsible for management and statistics, analysis and instructions, all sorts of organizations organize their whole staff to receive public fire safety education, while intermediaries engaging in public fire safety education are responsible for delivering lectures and trainings on public fire safety. In this way, a chain linked via proper laws and regulations is formed, each entity on which is responsible to perform their duties and obligations as per the requirements of laws and regulations, so that the public of the whole city is included in the public fire safety education and management.

Each organization can implement social fire safety regulation and education, training and examination, information input, statistics, analysis and tracking instruction and the like features based on the social fire safety regulation and education management information system platform which is based on ID card management information system, so to improve management and education efficiency and progressiveness and further realize full coverage of education and management.

Moreover, a fire safety evaluation index system with the public fire safety popularization and education as one of the evaluation indexes can be established to guarantee the implementation of urban public fire safety education.

The urban public fire safety education and management system and implementation plan are the guarantee for the far-ranging, long lasting and comprehensive implementation of urban public fire safety education.

Based on the above research results as well as the urban public fire safety education and management system and implementation mechanism plan, and in consideration of the far ranging and long lasting requirements of public fire safety education, the public fire safety education measures and implementation guarantee plans for each major occasion are studied ${ }^{3}$.

\subsection{Fire safety education for special posts}

As required by the acquisition of public fire safety capacities, the fire safety education for special posts should also be in line with the rules of individual fire safety capacity acquisition and development, supported by the implementation of the measures for the realizations of the above mentioned four stages, namely, external influence stimulus, subject reaction equilibrium, internal contradiction movement and individual behavior modification.

To meet the requirements of the four stages of fire safety capacities acquisition and development of special posts, the supporting full-process measures of educating, practicing, examining and managing should be implemented to guarantee the acquired fire safety knowledge and skills securely kept in mind and make the relevant fire safety behaviors acquired to become subconscious behaviors through repeated practices in daily work and life by virtue of mandatory requirements. In this way, it can guarantee the special post workers to develop the habit of following safety operation and activity requirements of special post, have 
the special post activities in a safe state to the greatest extent and contain the occurrence of accidents.

\section{How to Advance the Seven Advancements and How to Further Uphold it Effectively}

No matter what kind of environment the public is facing, the rules of the acquisition and development of public fire safety education are always the same.

Therefore, for how to advance the Seven Advancements and effectively uphold it, it is advisable to conduct proper studies following the procedures below and develop and further implement under the support of system mechanism the proper fire safety education measures related to educating, practicing, examining and managing:

(1) Research and develop fire safety knowledge and skill system necessary for the masses in different occasions, which shall include the following aspects:

1) Fire related theoretical knowledge

2) Main fire hazards and prevention and control and corrective measures

3) Fire emergency plan and evacuation drill plans

4) Fire escape knowledge and skills, including medical aid, and simulation drill and training acquisition methods

5) Fire prevention and fighting and fire escape related equipment and equipment configuration

6) Social fire safety skills training venues and members' participation mode

7) Construction of training venue rules and systems as per the rules of individual capacity acquisition and development

8) Key fire safety personnel cultivation plan, giving intensified training to key groups covering people responsible for fire safety, management, full-time and part-time fire fighters, control room operators, security guards, electric welders and so on to get them well understand fire safety

9) Teaching plans of fire safety publicity and education for employees

(2) Give simple expression of fire safety knowledge from the developed fire safety knowledge and skills system as per the need of specific occasions, relate the fire safety related research results to the daily work and life of specific occasion, and provide explanations and demonstrations derived from fire protection and safety theories and daily work and life of specific occasion for fire safety knowledge and skill system.

(3) Research and issue proper teaching materials and teaching aids for specific occasion

(4) Develop and implement fire safety skill training and examination schemes for employees

(5) Research education implementation guarantee plans for seven advancements in specific occasions based on comprehensive management and education system and mechanism mentioned in the paper and with reference to the management and education plans of our schools and communities.

(6) Finally, by virtue of the fire safety capacity management information system platform, as supported, encouraged and required by the national policies, and under the supervision, management, statistics and analysis and instruction of the government in combination with management and education network, each organization will organize all its people or following the guidance of the teaching materials and teaching aids developed based on the 
above studies, deliver fire safety publicity and education lectures and training for its people. Or, intermediaries and volunteer institutes may be entrusted to give such lectures and training.

\section{Conclusions}

Aiming at the problems existing in the work of fire protection publicity and education in China, and the present requirements presented by Chinese state and government, this paper gave an integrated scheme for how to carry out effective fire protection publicity and education in China through the following aspects:

\subsection{How to acquire and develop public fire safety capacities?}

This section studied the process of the public forming fire safety capacities by receiving fire safety education and self internalization, and shows that this process include four stages as following: external influence stimulus: direct stimulus, subject reaction equilibrium, internal contradiction movement and individual behavior modification.

\subsection{What kinds of measures can guarantee the acquisition and development of fire safety capacities of the public?}

In this section, the types of fire safety popularization and education measures supporting acquisition and development of public fire safety capacities were studied.

The principles of developing and implementing fire safety popularization and education measures were studied and gave the conclusion that targeted series, full-process measures of educating, practicing, examining and managing for supporting fire safety popularization and education should be implemented

Finally the series of educating, practicing and examining related facilities for publicity and education researched by the project team of Shanghai Fire Research Institute of MPS were introduced.

\subsection{How to guarantee all those measures to be implemented for all the public?}

In this section, a set of full-coverage public fire safety publicity and education system \& mechanism and fire safety education for special posts like schools and communities were suggested.

Under the guidance of above research results, this paper gave some suggestions about how to advance the Seven Advancements and how to further uphold it effectively.

\section{Recommendations}

Fire safety publicity, though minor and trivial, is a great thing for fire protection, and good results will be made as long as you preserve it ${ }^{5}$. It is time now for China to pay more attention and give more input to fire safety publicity and education, dramatically increase the efforts on the study of fire safety publicity and education, so to provide scientific support for fire safety publicity and education worker teams including fire department, truly upgrade the citizens' fire safety capacities and greatly cut the occurrence of fires and losses of life and property. 


\section{References}

1. X. Xiao, Thinking on How to Deepen Fire Protection Publicity [EB/OL], http://119.china.com.cn/zbjs/txt/2013-10/28/content_6411528.htm

2. Xinhuanet, Nine Ministries and Commissions Launch Opinions to Promote "Seven Advancements" Regarding Fire Protection Publicity and Education [EB/OL], http://news.xinhuanet.com/legal/2015-08/10/c_1116205799.htm

3. H. Wang, Study on Administrative and Educational Measures of China Urban Public Fire Safety Education [M], Beijing: China Social Sciences Publishing House, 2013

4. Q.Z. Zuo, Jing'an District, Shanghai: "Fire Safety Community workers" Bustling around Communities for Safety Inspection [EB/OL], http://news.cpd.com.cn/n12021581/n12021584/c13242150/content.html

5. M. P. Giesler. "Fire and Life Safety Educator". Delmar Cengage Learning. 2011. 237-238. 